\title{
The Sorption Capacity of Polymer Sorbents on the Basis of Polyimides with Crown Ethers
}

\section{ELENA ALEKSANDROVNA AVERINA, ANTON SERGEYEVICH YEGOROV*, OLGA VLADIMIROVNA KOSOVA and PAVEL ALEKSANDROVICH VOLKOV}

\author{
The Federal State Unitary Enterprise «Institute of Chemical Reagents and High Purity \\ Chemical Substances of National Research Centre «Kurchatov Institute» \\ 107076, Bogorodsky val, 3. Moscow, Russia. \\ ${ }^{*}$ Corresponding author E-mail: egorov@ irea.org.ru \\ http://dx.doi.org/10.13005/ojc/340108
}

(Received: August 30, 2017; Accepted: November 01, 2018)

\section{ABSTRACT}

In this work, polymeric sorbents based on polyimides with crown ethers for extraction of metal ions from aqueous environment were determined and investigated. The sorbents were made using various monomers (aromatic acid dianhydrides) and crown ethers. Samples of polymeric sorbents showed high values of the extraction extent of metals ions such as cobalt and cesium, and also good temperature resistance.

Keywords: Polymeric sorbents, Dianhydride aromatic acids, Crown-ethers, Metal ions, Polyimide, Sorption capacity.

\section{INTRODUCTION}

The presence of metal ions in various wastes, including the wastewater which are byproduct of industrial activities, is topical environmental problem. Unlike organic pollutants, heavy metal ions are not biodegradable and tend to accumulate in living organisms, many of them have toxic and carcinogenic effects. In this connection the problem of disposal of waste containing heavy metals is quite obvious.
With the help of membrane filtration technology can remove heavy metal ions with high efficiency, but is inherent in the method problems such as high cost, complexity of the process, contamination of the membrane and the low flow rate limit of its use.

It is known that various natural and synthetic neutral macrocyclic compound are able to bind in solution cations in such a way that the secondare included in the internal cavity of the 
molecule and are held there by intermolecular interactions with several polar groups (ether, amide or ester). It is particularly isolated donor-acceptor interaction in this complex formation. In addition, ion selectivity of such compounds in the complexation process was discovered, which depends not only on the number and nature of the ligand groups, but to a large extent determined by their molecular conformation. Due to this the specific features of individual macrocyclic chelators is able to show a pronounced selectivity for certain ions ${ }^{1}$.

Selective binding of metal ion with crown ether with the formation of supramolecule occurs as a result of the process of molecular recognition. The ability to molecular recognition is determined by interaction energy and conformation ${ }^{3}$. Non-covalent binding may occur selectively and may lead to the formation of the complex or supramolecule, which is characterized by thermodynamic and kinetic stability ${ }^{2,4}$.

Crown ethers are widely studied and used in various fields of science and industry. Application of crown ethers is determined, above all, by their selective ability to capture the cations of a certain size. The greatest distribution was received by crown-ethers containing as a heteroatom only the oxygen atoms. They are used in technological processes associated with the isolation and purification of salts of alkali and alkaline earth metals, in analytical studies and works related to synthesis, when you need to convert inorganic compounds from the aqueous phase in the organic environment as interphase catalysts. In radiochemistry, crown-ethers help to solve the problem of waste recycling in nuclear industries ${ }^{5}$.

The emergence of polymeric crown ether sorbents is due to the efficiency of their use as ligands for solvent extraction, sorption and chromatographic preconcentration and selective separation of metal ions.

Polymeric crown compounds (polymers with crown links) and grafted to a solid basis of crown-compound, being insoluble, Monomeric analogs are preferable because they're easier to handle and to regenerate. In addition, they are of interest in connection with high selectivity and speed of complex formation. Therefore, the synthesis of new polymeric crown ethers is an important task $\mathrm{k}^{6,7}$.

Currently known various methods of immobilization of crown ethers ${ }^{8}$.

Due to the formation of chemical bonds between functional groups of crown-compounds and functional groups of the polymer or silica that serve as solid carriers.

Impregnation of a solid porous carrier of the crown-compound.

Coating of inorganic surface of the solid support polymeric crown compounds.

Crown-ether fragments can be embedded in the polymer or be the boundaries of the macromolecular chains. Of special interest are nitrogen-containing heterocyclic compounds with opportunities for further funkcionisati, namely, deamination-esters. These connections can be source objects for creating functional polymeric sorbents capable of removing heavy metals.

The use of polyimides as matrices for the creation of a sorption material is important due to the unique properties of these compounds. Polyimides found application in various engineering fields ranging from microelectronics to high temperature adhesives and high-performance membranes.

Thermo-gravimetric analysis showed good thermal stability of aromatic polyimides. Basically, the polyimides are stable up to $440{ }^{\circ} \mathrm{C}$ in an inert atmosphere ${ }^{9-16}$.

\section{EXPERIMENTAL}

The process of obtaining a polymer sorbent on the basis of dianhydrides and crown ethers is a reaction of polycondensation with subsequent temperature imidization. Different dianhydride tetracarboxylic acidswere used as dianhydrides, diamino-dibenzocrown-etherswere used as diamines. 


\section{Materials and reagents}

Pyromellitic anhydride (PMDA), dianhydride 3,3', 4,4' - benzophenontetracarboxylic acid (BPDA), dianhydride 3,3', 4,4' - diphenylacetylene acid (FTFA) dianhydride 1,4-bis(3',4'dicarboxyphenoxy)-benzene (GHDFA) and diamino-dibenzocrown-esters were obtained by us earlier ${ }^{17,18}$. Mass fraction of basic substance was more than $97 \%$. Benzoic acid (BA) and $\mathrm{m}$-cresol were purchased from "Vekton".

\section{Preparation of polymeric sorbents}

In a three-neck flask with a volume of 250 $\mathrm{ml}$, equipped with a magnetic stirrer, reflux condenser, thermometer, tube for entry of inert gas were placed $90 \mathrm{ml}$ m-cresol, diamine-dibenzen-crown-ether, benzoic acid. The reaction mixture was stirred to dissolve the components. While stirring the calculated amount of dianhydride was added portionwise with the molar ratio of dianhydride to the diamine $1: 1$. The reaction mixture was kept 4 hours at the temperature of $80^{\circ} \mathrm{C}$, then $20 \mathrm{~h}$ at the temperature of $180^{\circ} \mathrm{C}$. At the end of imidization the obtained polymer was washed with ethanol for removal of meta cresol. The wash mixture was filtered and the operation repeated several times to complete washing out of meta-cresol. The resulting polymer was dried under vacuum at the temperature of $100-120^{\circ} \mathrm{C}$ for $6 \mathrm{~h}$ to achieve constant weight.

\section{RESULTS AND DISCUSSION}

The extent of imidization was determined by IR spectroscopy using IR-Fourier spectrometer Vertex 70 with Raman module. Most commonly used absorption bands kidney groups: $1780 \mathrm{~cm}^{-1}$ ( $\mathrm{C}=\mathrm{O}$ asymmetrical stretching), $1380 \mathrm{~cm}^{-1}$ (C-N stretching) and $725 \mathrm{~cm}^{-1}(\mathrm{C}=\mathrm{O}$ bending). The strongest band at $1720 \mathrm{~cm}^{-1}(\mathrm{C}=\mathrm{O}$ symmetrical stretching) also overlaps with the strong band of carboxyl group $(\mathrm{C}=\mathrm{O})$ at $1700 \mathrm{~cm}^{-1}$ polimetakrilates. Some overlapping of the characteristic imide bands at $1780 \mathrm{~cm}^{-1}$ and $725 \mathrm{~cm}^{-1}$ possible with the absorption bands of the anhydrides with $1780 \mathrm{~cm}^{-1}$ and $720 \mathrm{sm}-1$, respectively. Band carboxylic acid $1700 \mathrm{~cm}^{-1}(\mathrm{C}=\mathrm{O})$ and 2800-3200 $\mathrm{cm}^{-1}(-\mathrm{OH})$ and amide bands at $1660 \mathrm{~cm}^{-1}(\mathrm{C}=\mathrm{O}), 1550 \mathrm{~cm}^{-1}$ $(\mathrm{C}-\mathrm{N}-\mathrm{H})$ and $3200-3300 \mathrm{~cm}^{-1}(\mathrm{~N}-\mathrm{H})$ is usually facing the broad peaks are also useful for qualitative evaluation of the process of imidazole ${ }^{19}$.
To determine the thermal stability without degradation of the built graph in the coordinates temperature - weight, find the first drop of the mass on the graph corresponding to the decomposition of the sample. Temperature resistant without destruction is determined by the intersection of the tangent to the graph of mass change before and after bending. The measurement is carried out using a thermal analyzer TA Instruments SDT Q 600 for the simultaneous DSC/TGA/DTA analysis.

\section{Evaluation of the degree of extraction and sorption capacity}

As a standard sample used solutions with a concentration of the element $1 \cdot 10^{-3} \mathrm{M}$, prepared from reagent qualification "analytical grade". To determine the extent of extraction of cations a portion of $0.1000 \pm 0.0002 \mathrm{~g}$ of the investigated sorption material was placed into the solution with a given concentration of the cation. The resulting mixture was stirred for a certain number of hours to establish equilibrium between the sorbent phase and the aqueous solution containing the designated cation. The residual concentration of the cation in the solution was determined for $\mathrm{Co}^{2+}$ by atomic emission spectrometer with inductively coupled plasma, and $\mathrm{Cs}^{+}$on the mass spectrometer with inductively coupled plasma.

The results were processed by the formulae:

$S=\frac{C_{1}-C_{2}}{C_{1}} \cdot 100 \%$,

$E=\frac{\left(C_{2}-C_{1}\right) * V_{\text {solv }}}{m_{\text {sorb }}}$

where $S$ isextent of extraction, $\%$; E-sorption capacity, M cations/g sorbent; $\mathrm{C}_{1}$-concentration of cation in the initial solution, $\mathrm{mol} \cdot \mathrm{L}^{-1} ; \mathrm{C}_{2}$-concentration of cation in solution after sorption, $\mathrm{mol} \cdot \mathrm{L}^{-1} ; \mathrm{m}_{\text {sorb }}$ - mass of sorbent, $\mathrm{g} ; \mathrm{V}_{\text {solv }}$ - volume of solution, I.

The analysis of concentration of metal ions in solution was performed by atomic emission spectrometer with inductively coupled plasma method (ICP-AES) iCAP 6300 Duo dual plasma 
review software iTEVA and mass spectrometer with inductively coupled plasma method (ICP-MS) ELAN DRC-e PerkinEImer

The results of the experiment are shown in Tables. 1 and 2. The data obtained confirm the affinity of the ring size of crown ether for cesium ions, since the degree of extraction of ions of cesium in all cases exceeds the degree of extraction of cobalt ions.

Were also tested samples of polymer, differing only by the presence of amine-benzencrown-ether AB-15-s-5 (Table. 2).

In the absence of crown ether at the boundaries of the polymer chain, there is a sharp increase in the extent of extraction of cobalt ions and a decrease in the extent of extraction of cesium ions. The decline of this value was assumed as long as the sorption of cesium ions occurs due to the ring of the crown ether. Increase the degree of extraction of cobalt ions in this case occurs due to their preferential sorption obviously at the expense of van-der-waals forces and physical adsorption, where the crucial role is played by the length of the polymer chain. In the presence of monomer AB-15-to- 5 on the ends of the chain growth is significantly reduced, respectively, the sorption of cobalt ions decreases.

We also conducted experiments to assess the impact on the degree of extraction exposure time of sorbents in the studied solution as well as the impact and necessity of constant stirring (Figure. 1, 2)

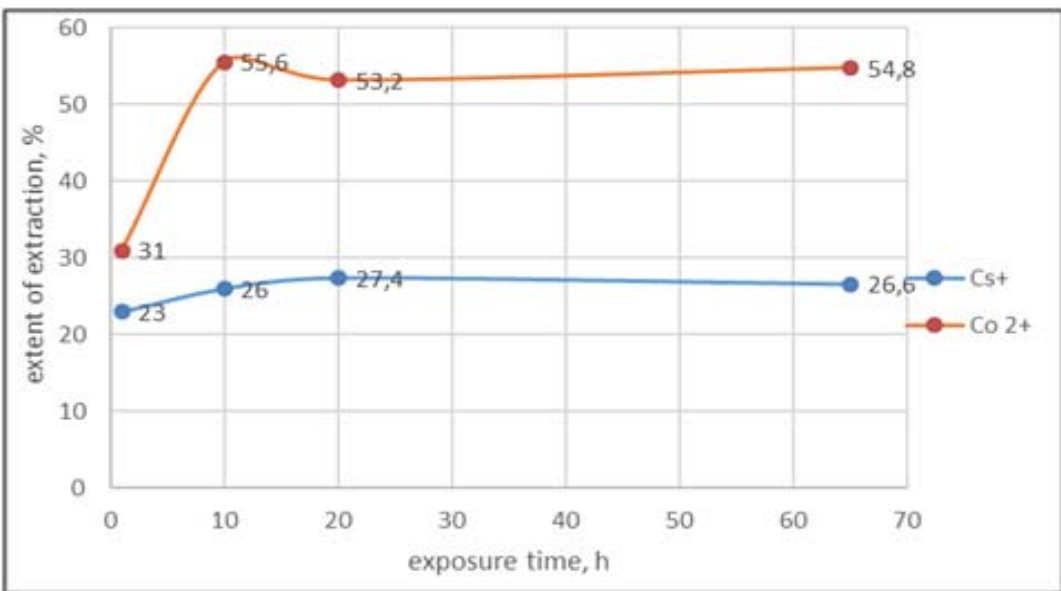

Fig. 1. the extent of extraction of ions of cobalt and cesiumby sorbent BPDA/DADB-18-crown-6, depending on the exposure time

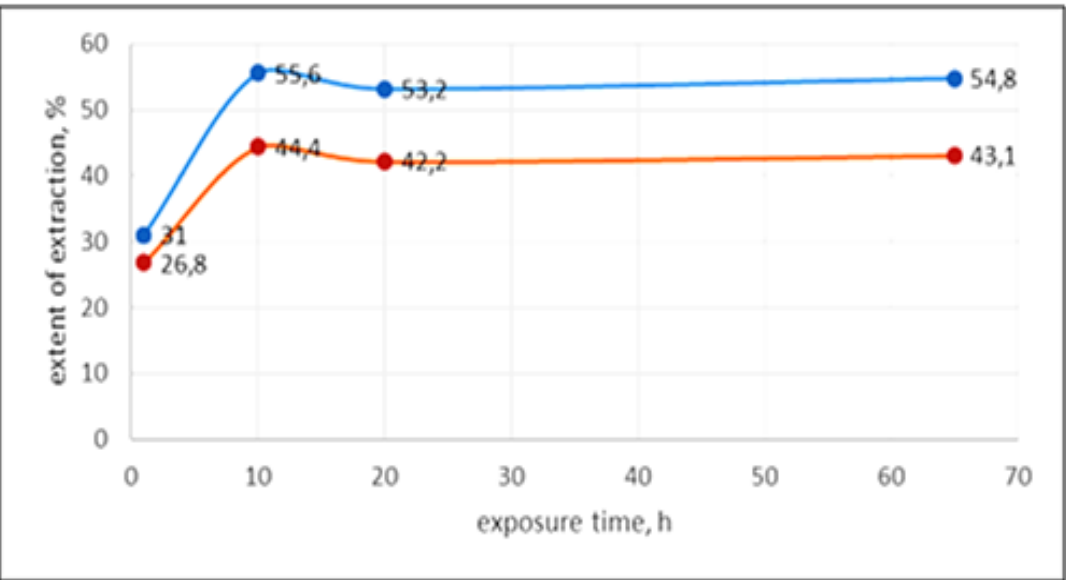

Fig. 2. the extent of extraction of cesium ions by sorbent AB-15-crown-5/ FTFA/DADFS depending on the exposure time with and without stirring 
The data obtained showed that the time factor affects the degree of extraction of ions within 10 hours. Most of the samples showed the achievement of maximum sorption capacity while maintaining in the solution to 7-9 $\mathrm{h}$ further increase the time in 2 and more times does not lead to change. Stirring or stationary mode of exposure has little effect on the result of sorption. Upon exposure of samples of sorbents in a solution of no more than one hour stirring almost no effect on the result, although a slight increase in the degree of extraction with stirring compared to the stationary regime is observed upon exposure time of $10 \mathrm{~h}$ or more.

\section{Thermal properties}

Table. 3 shows the heat resistance, glass transition temperature $(\mathrm{Tg})$ and stability of thermo-oxidative degradation of the polymer sorbents based on polyimides with crown ethers. The TGA graphs of GHDFA/DADB-21-crown-7 are shown on Figure. 3.

Table. 3. Temperature loss of $5 \%$ and $10 \%$ of the mass of experimental samples of polymer sorbents in an inert atmosphere and in the air

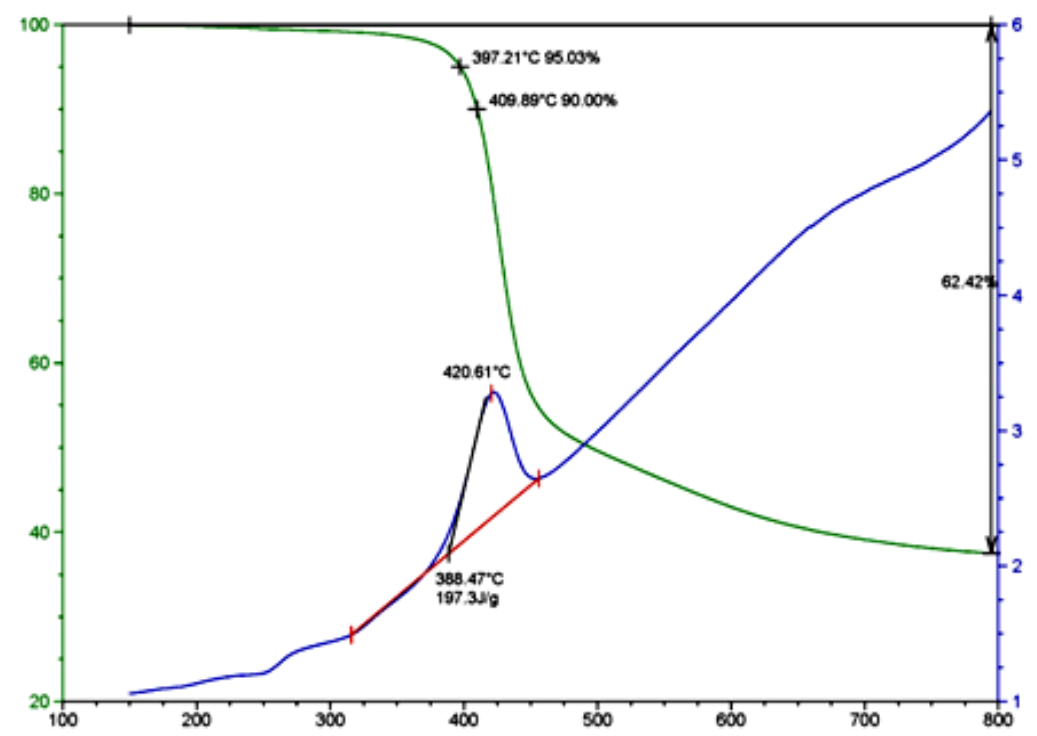

(a)

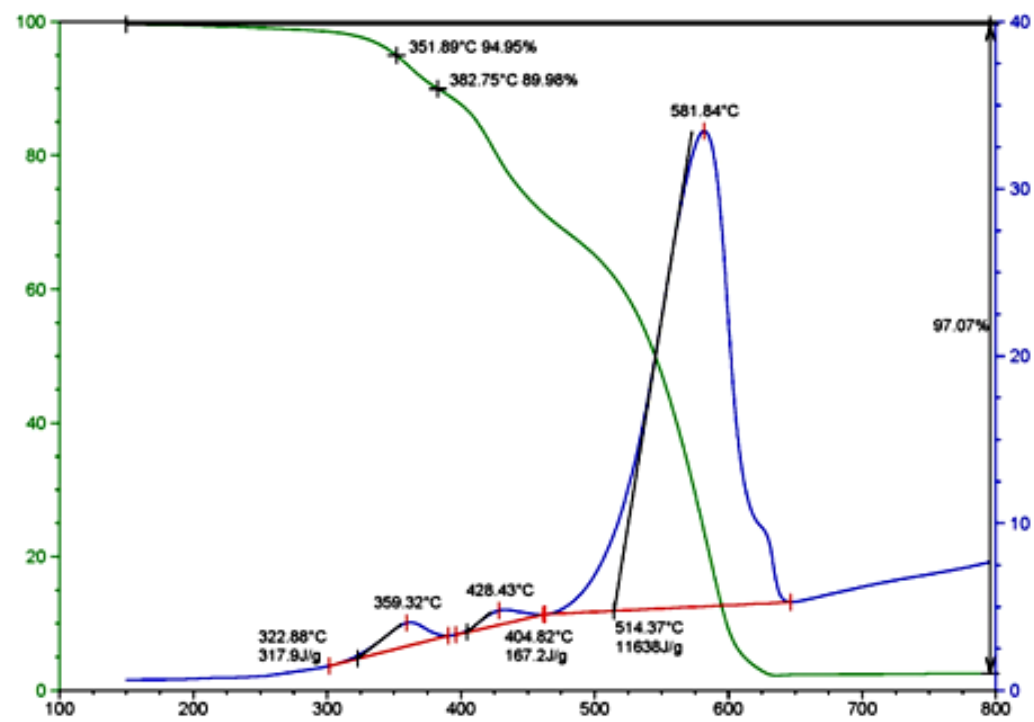

(b)

Fig. 3. The TGA draphs of sorbent GHDFA/DADB-21-crown-7 in argon (a) and air(b) 
YEGOROV et al., Orient. J. Chem., Vol. 34(1), 75-85 (2018)

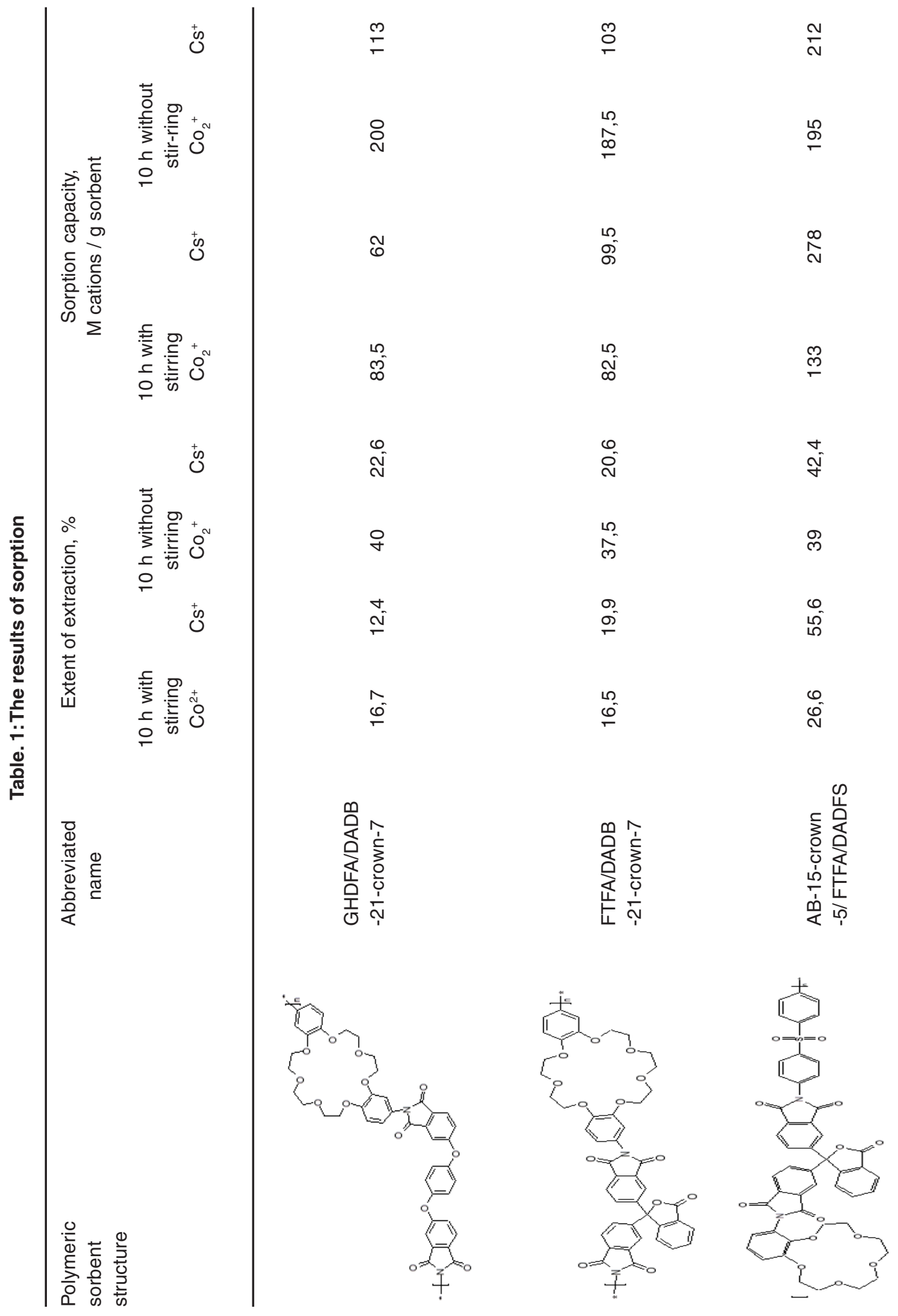


YEGOROV et al., Orient. J. Chem., Vol. 34(1), 75-85 (2018)

은 온

$\stackrel{\text { กิ }}{2}$

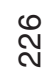

న్

孚 年

$\stackrel{\llcorner}{\stackrel{\circ}{\circ}}$

$\stackrel{2}{\stackrel{2}{N}}$

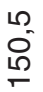

กิ

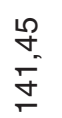

$\stackrel{m}{\longrightarrow}$

㐫

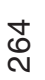

๙

मे

용

$\stackrel{\oplus}{\sim}$

$\stackrel{5}{\leftarrow}$

ก $\stackrel{\infty}{\stackrel{\infty}{N}}$

$\stackrel{+}{\stackrel{d}{d}}$

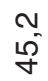

$\stackrel{+}{\dot{c}}$

$\begin{array}{ll}\text { N } & \text { Dे }\end{array}$

ल

ले

$\overline{0}$

$\begin{array}{ll}\text { N } & \text { N } \\ \text { N } & \text { No }\end{array}$

$\stackrel{0}{\infty}$

$\infty$
$\infty$
டீ

ஸิ กิ

$\stackrel{\infty}{\infty}$

$\stackrel{\infty}{\infty} \underset{\infty}{\infty}$

$\stackrel{\circ}{\wedge}$

ลูก

$\stackrel{乛}{2}$

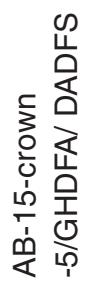

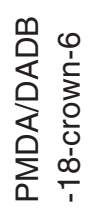

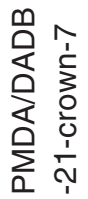

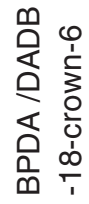

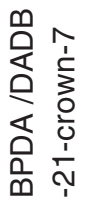
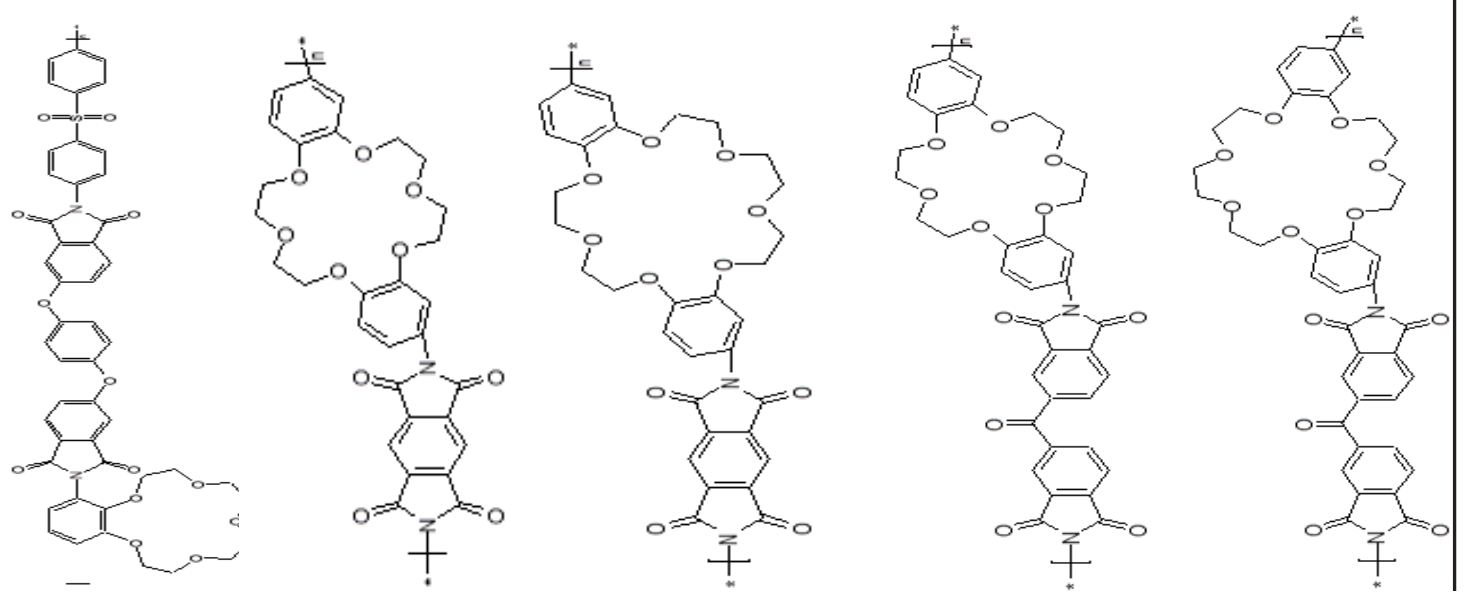


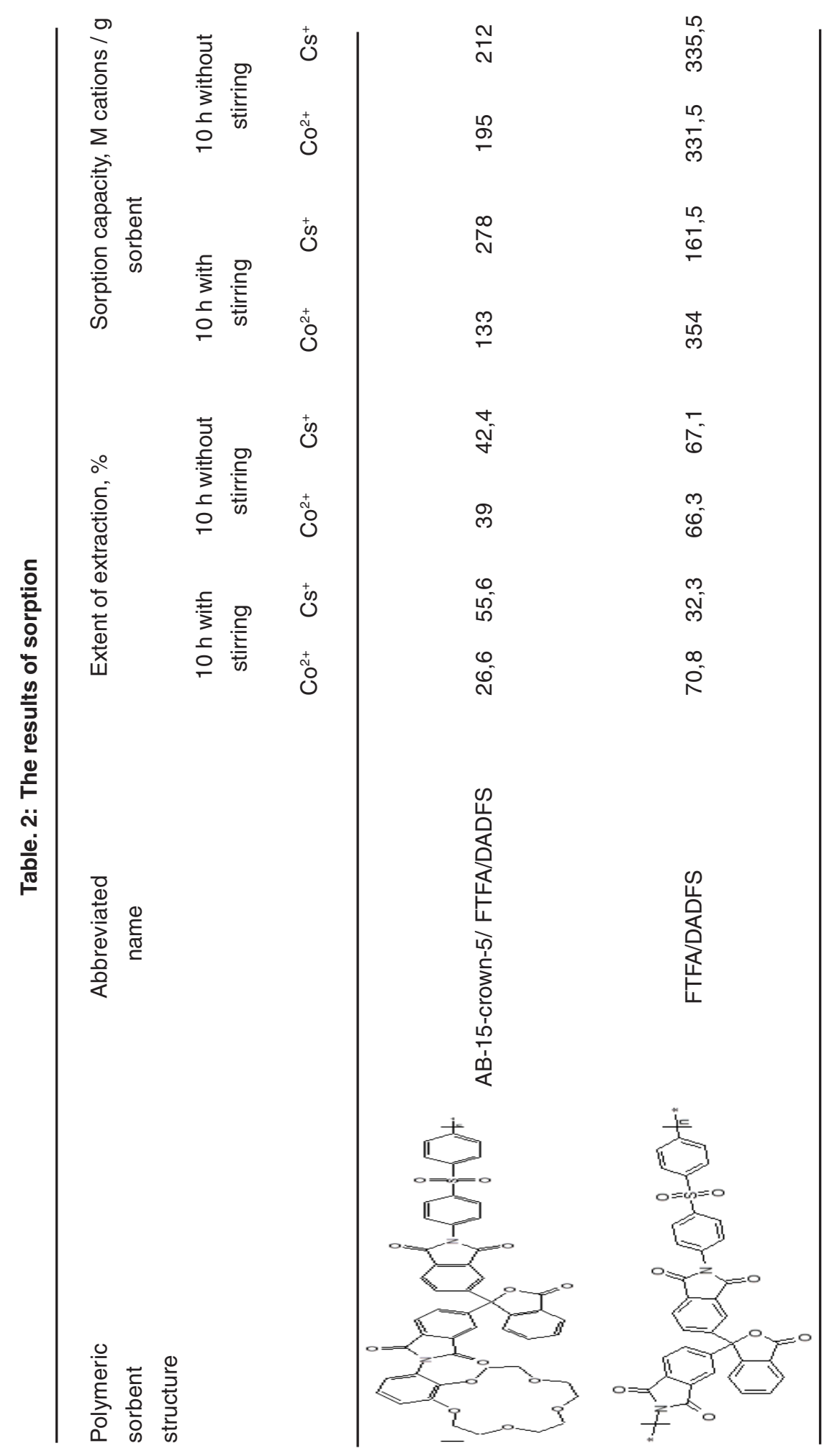


Table. 3: Temperature loss of $5 \%$ and $10 \%$ of the mass of experimental samples of polymer sorbents in an inert atmosphere and in the air

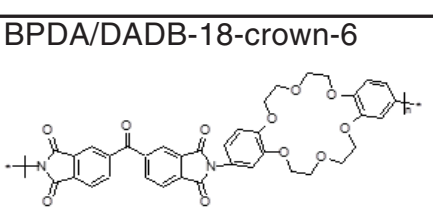

BPDA/DADB-21-crown-7

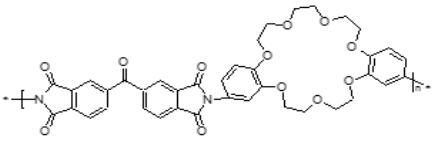

GHDFA/DADB-18-crown-6

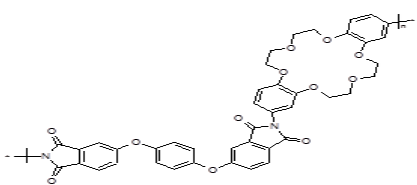

GHDFA/DADB-21-crown-7

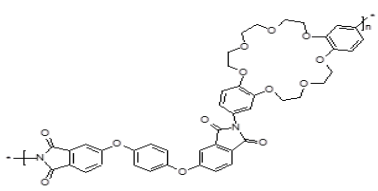

PMDA/DADB-18-crown-6

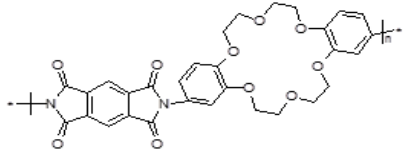

FTFA/DADB-18-crown-6

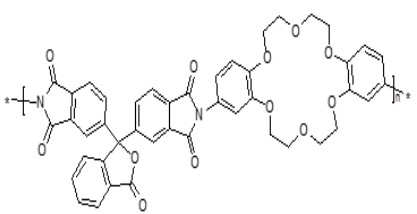

AB-15-crown-5/GHDFA/DADFS

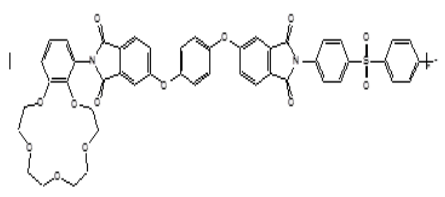

AB-15-crown-5/FTFA/DADFS

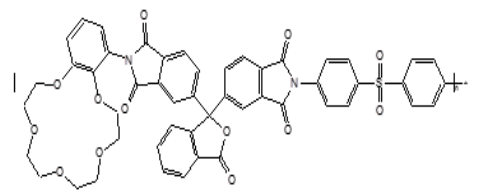

$382 / 407$

$405 / 417$

422

$342 / 361$

$399 / 445$

357

$383 / 410$

$394 / 408$

425

$352 / 383$

$397 / 410$

428

$369 / 392$

$385 / 405$

377

$385 / 445$

$378 / 406$

$359 / 423$

$325 / 351$

342 
On the basis of obtained data it is possible to observe an increase in thermal stability with increasing ring size and accordingly a molecular weight of crown ether. If you compare the polymers with different dianhydride, in an inert atmosphere greatest resistance showed a polymer with pyromellitate dianhydride (PMDA) and diamino-dibenzo-21-crown 7, air dianhydride 3,3-bis-(3,4-dicarboxyphenoxy) phtalic (FTFA).

\section{CONCLUSIONS}

The polymer sorption materials based on polyimide matrix with crown-ethers have high values of thermal resistance, allowing to use the obtained data for the development of technology for industrial sorbents used in high-temperature environments. Also samples of polymer sorbents showed the possibility of selective extraction of metal ions, for example cobalt and cesium. Has been studied by a number of factors affecting the degree of metal ions extraction and the optimal conditions for maximum sorption capacity of the polymer sorbents.

\section{ACKNOWLEDGEMENT}

This recherches was conducted by the financial support of the state represented by the Ministry of Education in the framework of the Agreement on granting a subsidy 14.625.21.0034 October 27, 2015 (the Unique identifier of applied research (project) RFMEFI62514X0034).

\section{REFERENCES}

1. Tunca, U.; Yagci, Y. Crown ether-containing polymers. Prog. Polym., 1994, 19, 223-286.

2. Sakamoto, H.; Kimura, K; Shono, T. Protondriven cation transport through polyamic acid membranes incorporating crown ether moiety. Eur. Polym. J., 1986, 22(2), 97-101.

3. Pethrick, R.A.; Wilson, M.J.; Affrossman, S.; Holmes, D.; Lee, W.M. Synthesis and cation complexation properties of crown ether polyamic acids/imides. Polymer., 2000, 41, 7111-7121.

4. Irvin, J.A.; Stasko, D.; Fallis, S.; Guenthner, A.J.; Webber, C.; Blackwell, J. Polyimides for battery and fuel cell membranes. Fuel Chemistry Division Preprints., 2003, 48, 441-442.

5. Yang, L.; Kang, Y.; Wang, Y.; Xu, L.; Kita, H.; Okamoto, K. Synthesis of crown ethercontaining copolyimides and their pervaporation properties to benzene/ cyclohexane mixtures. Journal of Membrane Science., 2005, 249, 33-39.

6. Lindsay, G. A.; Miles, M. H.; Zarras, P.; Fallis, S.; Yee, R. Y.; Chafin, A. P.; Merwin, L. H. New Main-Chain Crown-Ether Polyimides for Lithium-Ion Battery Membranes. Conference: Battery Conference on Applications and Advances., 1999, 43-46.
7. Feigenbaum, W.M.; Michel, R.H. Novel polyamides from macrocyclic ethers. Polym. Sci., 1971, 9, 817-820.

8. Kimura, K.; Maeda, T.; Shono, T. Extractraction of alkali metal picrates with poly- and bis(crown ether)s. Talanta., 1979, 26, 945-949.

9. Jie Ju X., Chu L., Mi P., Song H., Moo Lee Y. Synthesis and Characterization of a Novel Thermo-Sensitive Copolymer of $\mathrm{N}$ Isopropylacrylamide and Dibenzo-18crown-6-diacrylamide. Macromol. Rapid. Commun., 2006, 27, 2072-2077.

10. Khazaeia, A.; Saedniaa, S.; Kiani Borazjanib, M.; Saiena, J.; Kianib, M.; Afkhami, A. A novel covalent functionalisation of poly (styrenealt-maleic anhydride) with 4-amino benzo9-crown-3 ether. Supramolecular Chemistry., 2014, 26(2), 88-93.

11. Cinquini, M.; Colonna, S.; Molinari, H.; Montanari, F. Synthesis of Alkyl-Substituted Crown Ethers: Efficient Phase-transfer Catalysts. J. Amer. Chem. Soc., 1976, 98, 394.

12. Liou, G.S.; Hsiao, S.H.; Chen, H.W. Novel high-Tg poly(amine-imide)s bearing pendent $\mathrm{N}$-phenylcarbazole units: synthesis and photophysical, electrochemical and electrochromic properties.J. Mater. Chem., 
2006, 16, 1831-1842.

13. Blasius, E.; Janzen, K.P. Preparation and application of polymers with cyclic polyether anchor groups. Pure \& Appl.Chem., 1982, 54(11) 2115-2128.

14. Dotsevi, G.; Sogah, C.D.; Cram, D.J. Total Chromatographic Optical Resolutions of aAmino Acid and Ester Salts through Chiral Recognition by a Host Covalently Bound to Polystyrene Resin. J. Amer. Chem. Soc., 1976, 98, 3038-3041.

15. Sogah, C.D.; Cram D.J. Host-Guest Complexation. Host Covalently Bound to Polystyrene Resin for Chromatographic Resolution of Enantiomers of Amino Acid and Ester. Journal of the American Chemical Society., 1979, 101, 3035-3042.
16. Walsh, C.J.; Mandal, B.K. A new class of aromatic dianhydrides for thermostable polyimides.Chem. Mater., 2001, 13, 2472-2475.

17. Glushko, V. N.; Sadovskaya, N.Y.; Kozhuhov, V. I.; Blokhina, L. I.; Antropova, I. A.; Petina, E. S.; Retiviov, V. M.; Melnikova, E. Y. Production of Macrocyclic Polyether Benzo-15-Crown-5 and its Functional Derivatives. Orient. J. Chem., 2017, 33(4), 1689-1697

18. Yegorov, A.S.; Wozniak, A. I.; Ivanov, V. S.; Averina, E. A.; Zhdanovich, O.A. Development and Optimization of Producing 3,3', 4,4'-benzophenonetetracarboxylic dianhydride. Orient. J. Chem., 2016, 32(6), 3063-3070

19. Goto, K. Polyimides (elementary and applications).Polyimides., 2002, 270-271. 